\title{
Saúde, Pesquisa Teórica e Sistema Jurídico
}

\section{Health, Theoretical Research and Legal System}

\section{Salud, Investigación Teórica y el Sistema Legal}

\author{
Neuza Maria de Fátima Guareschi \\ Universidade Federal do Rio Grande do Sul, RS, Brasil.
}

É com imensa satisfação que o Conselho Federal de Psicologia (CFP), juntamente com todo o Sistema Conselhos de Psicologia, apresenta o primeiro número de 2017 do periódico "Psicologia: Ciência e Profissão". Primeiramente, gostaríamos de agradecer a todos os autores, pareceristas e equipe editorial que durante os três últimos anos conduziram a produção desta publicação científica. A gestão do XVII Plenário do CFP, juntamente com todo o corpo editorial, aposta na difícil tarefa que é hoje organizar, viabilizar e manter um periódico científico, reconhecendo que o saber psicológico é constituído por uma diversidade de abordagens teóricas, práticas profissionais e de pesquisa. Assim, a atual gestão entende que é responsabilidade do CFP e do Sistema Conselhos criar condições para o desenvolvimento teórico da Psicologia criando espaços de diálogo entre as práticas profissionais e as agências de formação e seus grupos de pesquisa, contribuindo para os processos de produção de conhecimento em Psicologia a partir das mudanças pelas quais o campo psi tem passado, mas, principalmente, como um modo de enfrentamento ao atual cenário político e econômico do país.

Tendo sempre presente o objetivo da Revista "Psicologia: Ciência e Profissão", que é o de contribuir para a formação profissional do psicólogo brasileiro bem como socializar o conhecimento psicológico produzido por aqueles que pesquisam e/ou atuam no campo da Psicologia, neste número apresentamos 17 artigos de diversas áreas da Psicologia, de várias temáticas deste campo de saber e elaborados a partir de diferentes abordagens teóricas e metodológicas. Sabemos que a multiplicidade epistemológica é uma característica do campo psicológico. Figueiredo (2017), em seu livro "A Invenção do Psicológico: Quatro Séculos de Subjetivação", aponta para três movimentos na constituição deste campo, como o que caracteriza as diferentes psicologias. Estas diferenciações teóricas e metodológicas dizem respeito não somente às diferenciações dos objetos de estudo que vêm sendo produzidos historicamente, mas também à dimensão prática e profissional deste campo de saber.

Estas 17 produções científicas podem ser agrupadas, basicamente, em três grandes grupos temáticos de áreas do conhecimento da Psicologia. São eles: Saúde, Pesquisas sobre produções teóricas e Sistema Judicial. Entretanto, antes de referenciarmos as produções do grupo temático da saúde, iniciamos apresentando o artigo "Qualidade de Vida e Valores nas Organizações: Impactos na Confiança do Empregado”, de Uanisléia Lima da Silva e Áurea de Fátima Oliveira, que, embora não seja especificamente da saúde, sem dúvida, remete a esta questão por tratar de Qualidade de Vida e Trabalho. Neste estudo as autoras verificam o poder de predição da percepção de valores organizacionais e da qualidade de vida no trabalho sobre a confiança do empregado na organização.

Os sete artigos que apresentamos a seguir no periódico abordam de forma mais direta a problemática da saúde e foram realizados com diferentes grupos populacionais e de contextos bem específicos deste campo de atuação dos profissionais da Psicologia. O primeiro artigo, "Ressignificando a Prática Psicológica: o Olhar da Equipe Multiprofissional dos Centros de Atenção Psicossocial”, de Juliana Cantele e Dorian Mônica Arpini, objetiva compreender a prática psicológica através do olhar das equipes de saúde mental por meio de um estudo qualitativo, no 
qual é apontada a importância da escuta deste profissional da Psicologia na equipe-família-sociedade. Já, o segundo artigo deste grupo temático, de Mariana Sarkis Braz e de Maria Helena Pereira Franco, intitulado "Profissionais Paliativistas e suas Contribuições na Prevenção de Luto Complicado", analisa a formação dos profissionais que integram a equipe de cuidados paliativos em relação ao processo de morrer do paciente e as percepções destes profissionais em relação às suas contribuições para a prevenção de luto. Os resultados indicam que a formação dos profissionais em relação ao processo de morrer é escassa, especialmente para o contexto do processo de luto.

Os próximos três artigos do grupo dos sete que estão relacionados com a temática da saúde, cada um dentro das características específicas de uma determinada patologia, apresentam estratégias de enfrentamento desenvolvidas pelos pacientes em relação à doença. $\mathrm{O}$ artigo "O Vazio de Sentido: Suporte da Religiosidade para Pacientes com Câncer Avançado", de Cristine Gabrielle da Costa dos Reis, Camila Peixoto Farias e Alberto Manuel Quintana, trata de pacientes com câncer avançado. Nele, as autoras e o autor tentam compreender quais os sentidos que os pacientes constroem para a vivência do adoecimento, na qual verificam que os sentidos para sua vivência se dão predominantemente por meio da religiosidade. Já o artigo de Camila Carrascoza Vasco e de Maria Helena Pereira Franco, "Indivíduos Paraplégicos e o Significado Construído para a Lesão Medular em suas Vidas”, discute os significados construídos pelo acometimento da lesão medular traumática em jovens. O texto aponta que estes significados são positivos e contribuem para o direcionamento de um novo projeto de vida. Por último, o artigo "Potencialidade do Lúdico como Promoção de Bem-estar Psicológico de Pacientes em Hemodiálise" mostra como atividades lúdicas podem propiciar relaxamento durante sessões de hemodiálise. Os autores Tailah Barros de Paula, Beatriz Maia Souza, Natan Medeiro, Samira Mouhssen El Malt, Flavia Gutierrez, Lara D’Ávila Lourenço e Karina Franco Zihlmann indicam que estas atividades provocam uma melhora relativa do humor, além de permitirem a expressão de necessidades subjetivas singulares.

Os dois últimos artigos do bloco temático da saúde tratam mais especificamente da população de idosos, através de um caso único, e de adolescentes do sexo masculino, por meio de um estudo de caso transgeracional. No artigo “'Salva o Velho!': Relato de Atendimento em Psicologia Hospitalar e Cuidados Paliativos", Fabíola Langaro apresenta o relato de atendimento de um paciente com diagnósticos de doenças crônicas e com indicação para tratamento em cuidados paliativos. O foco da discussão centra-se em como o acompanhamento psicológico pode trabalhar na mediação dos conflitos familiares e na comunicação paciente-família-equipes nesta situação diagnóstica e com esta população. Já o artigo de Élide Dezoti Valdanha-Ornellas e de Manoel Antônio dos Santos, "Transtorno Alimentar e Transmissão Psíquica Transgeracional em um Adolescente do Sexo Masculino", investiga a transmissão psíquica dos cuidados em três gerações de uma família que tinha um de seus membros acometidos pelo transtorno da anorexia nervosa. Os autores apontam a necessidade de incluir os familiares no tratamento para torná-los conscientes dos processos psíquicos envolvidos, permitindo que a família se reorganize emocionalmente.

O bloco temático que apresentamos a seguir é referente a seis artigos que tratam de pesquisas teóricas direcionadas a abordagens teóricas, conceitos, instrumentos e literatura para a formação profissional. Os três primeiros artigos desenvolvem as pesquisas teóricas por artigos que são buscados, principalmente, através de base de dados de publicações científicas como Scientific Electronic Library Online (SciELO) e Periódicos Eletrônicos em Psicologia (PePSIC), Redalyc e Lillacs entre outros. No primeiro deles, "Terapia de Casal e Estratégias de Resolução de Conflito: uma Revisão Sistemática”, Crístofer Batista da Costa, Marina Zanella Delatorre, Adriana Wagner e Clarisse Pereira Mosmann buscam estas bases de dados para uma revisão sistemática de artigos científicos sobre psicoterapia de casal e estratégias de resolução de conflito e para identificar variáveis envolvidas no processo terapêutico. A análise da literatura forneceu um panorama internacional, composto por perspectivas de consenso já estabelecidas, inconsistências que devem ser superadas e carência de estudos, especialmente no Brasil, contexto potencial de investigação da temática. Já o artigo "Depressão em Adolescentes: Revisão da Literatura e o Lugar da Pesquisa Fenomenológica", de Anna Karynne Melo, Adolfo Jesiel Siebra e Virginia Moreira, busca as bases de dados para identificar e discutir os estudos que estão sendo produzidos sobre depressão em adolescentes. A pesquisa evidenciou cinco categorias temáticas associadas à depressão em adolescentes e depressão e suicídio em adolescentes. Os eixos 
abordados demonstram que ainda existe muito a discorrer sobre essa forma de adoecimento, em virtude dos múltiplos contornos que a constituem. O terceiro artigo que busca a base de dados, "Análise da Produção Científica Brasileira sobre o Teste das Matrizes Progressivas de Raven", o faz com o objetivo de quantificar e analisar a produção científica brasileira de artigos a respeito do Teste das Matrizes Progressivas de Raven. Lucila Moraes Cardoso, Érica Ive Xavier Lopes, Jamille Cavalcante de Oliveira e Aline Pinheiro Braga mencionam que as produções foram publicadas no período entre 1995 e 2014 e, em sua maioria, eram provenientes da região Sudeste brasileira, referem o uso do teste de Raven em contextos específicos e poucas buscaram analisar as qualidades psicométricas do instrumento, evidenciando a demanda de mais estudos sobre as qualidades psicométricas do teste de Raven.

Os outros três últimos artigos que compõe o bloco dos seis que compreendem as produções deste número da Revista "Psicologia: Ciência e Profissão" sobre pesquisas teóricas dizem respeito a investigações sobre o desenvolvimento histórico de conceitos e literatura que auxiliem na formação profissional, mais especificamente, de condutores de transporte rodoviário. $\mathrm{O}$ artigo "Prática Baseada em Evidências em Psicologia e Idosos: Conceitos, Estudos e Perspectivas", de Thiago Vinicius Monteleone e Carla Witter, apresenta o desenvolvimento histórico do conceito de Prática Baseada em Evidências em Psicologia. Através das influências científicas, clínicas e de associações de classes, este estudo demonstra o desenvolvimento bem como a integração deste modelo à prática clínica com a população idosa pelos principais estudos existentes e as perspectivas para a obtenção de evidências empíricas do resultado psicoterápico para esta população. Como resultado de uma pesquisa bibliográfica, de caráter histórico e teórico, o artigo "Os Fundamentos da Técnica da Transferência de 1895 a 1905” de Fabiano Chagas Rabêlo, Leonardo Danziato, Carlos José Cerqueira Veras Filho, Rodrigo Barbosa Silva Quadros e Gustavo Oliveira Carvalho mostra, de modo pormenorizado, a discussão em Freud sobre a transferência no período que vai de sua primeira descrição clínica até sua conceituação. O objetivo é problematizar o manejo da transferência na clínica, o modo pelo qual este conceito foi construído quanto o seu conteúdo teórico, salientando que a transferência está no cerne do debate sobre a especificidade do método psicanalítico. Como anunciado anteriormente, o próximo artigo trata de um estudo teórico pretende contribuir com o debate sobre o uso de simuladores nos processos de formação para os profissionais de transporte terrestre rodoviário. Thiago Drumond Moraes, Paulo César Zambroni-de-Souza e Yves Schwartz, em "Os Usos de Simuladores Durante a Formação Profissional para a Condução de Transportes Rodoviários", analisam criticamente, a partir da produção acadêmica sobre uso de simuladores, suas potencialidades em situações de formação para condutores profissionais, a partir de uma perspectiva ergológica que permite a articulação com outras clínicas do trabalho. Os autores evidenciam que os processos de formação profissional mediado pelo uso de simuladores podem ser pertinentes para a grave situação do trânsito brasileiro, embora se reconheça a ausência de pesquisas nacionais sobre a temática.

Os três últimos artigos que encerram esta primeira edição da Revista "Psicologia: Ciência e Profissão" tratam de uma temática muito importante do profissional da Psicologia no cenário atual da sociedade brasileira. Os processos de judicialização da vida têm estado presentes mais do que nunca no cotidiano das práticas psi. Assim, o primeiro artigo, "A Defensoria Pública e Cuidados em uma Relação de Cuidado: um Estudo de Caso", apresenta uma discussão sobre a atuação do psicólogo na Defensoria a partir do lugar processual do assistente técnico, especialmente compreendido dentro das políticas públicas que trabalham com famílias necessitadas nos termos da lei. Nele, Marcos Antonio Barbieri Gonçalves e Raquel Souza Lobo Guzzo apontam para o discurso na Psicologia que mantém a lógica de legislações anteriores ao Estatuto da Criança e do Adolescente, em que se culpabiliza a família pobre em processos de destituição do poder familiar, e para teorias que associam pobreza com a incapacidade de cuidar dos filhos. O segundo artigo discute a alienação parental como uma forma de abuso emocional que pode estar presente em processos judiciais envolvendo disputas de guarda através da análise de laudos psicológicos. Em "Perícias Psicológicas em Processos Judiciais Envolvendo Suspeita de Alienação Parental”, Ilana Luiz Fermann, Luísa Fernanda Habigzang, Daniela Inaiá Chambart, Laura Nichele Foschiera e Thays Carolyna Pires Mazzini Bordini indicam que não há um padrão para avaliação de avaliação psicológica adotado pelos profissionais da Psicologia que trabalham nesta área de perícias e que os problemas quanto à adequação de documentos sugerem a necessidade de maior capa- 
citação profissional para atuação na área. O último artigo deste bloco e dos que compõem esta edição do periódico apresenta o tema da laicidade remetendo aos debates que o CFP têm realizado sobre a necessidade de adoção de posturas democráticas nos debates públicos atuais, especialmente, em relação à "cura gay", a "ideologia de gênero", às políticas públicas de saúde e ao credenciamento de cursos de graduação em Psicologia. A Edição Conselho Regional de Psicologia SP - CRP 06, da coleção Psicologia, Laicidade e as Relações com a Religião e a Espiritualidade, no Volume 1 - Laicidade, Religião, Direitos Humanos e Políticas Públicas, São Paulo, 2016, reforça que a laicidade da ciência e das práticas em Psicologia significaria vincular esta temática à questão ética e técnica profissional. Desta forma, no artigo intitulado "Laicidade e Conselho Federal de Psicologia: Dinâmica Institucional e Profissional em Perspectiva Jurídica", Roger Raupp Rios, Alice Hertzog Resadori, Rodrigo da Silva e Daniel Martins Vidor examinam os fundamentos e o modelo da laicidade constitucional no Brasil e refletem sobre as consequências desse modelo para a vida institucional e o acompanhamento dos profissionais pelo CFP e Sistema Conselhos.

\title{
Referências
}

Figueiredo, L. (2007). A invenção do psicológico: quatro séculos de subjetivação: 1500-1900. São Paulo: Escuta.

\author{
Neuza Maria de Fátima Guareschi \\ Universidade Federal do Rio Grande do Sul \\ Editora \\ Email: neuza.guareschi@cfp.org.br
}

Como citar: Guareschi, N. M. F. (2017). Saúde, pesquisa teórica e sistema jurídico. Psicologia: Ciência e Profissão, 37(1), 3-6. https://doi.org/101590/1982-3703003712017

How to cite: Guareschi, N. M. F. (2017). Health, theoretical Research and legal system. Psicologia: Ciência e Profissão, 37(1), 3-6. https:// doi.org/101590/1982-3703003712017

Cómo citar: Guareschi, N. M. F. (2017). Salud, investigación teórica y el sistema legal. Psicologia: Ciência e Profissão, 37(1), 3-6. https:// doi.org/101590/1982-3703003712017 